\title{
Summary: Zivilgesellschaft im Überblick
}

\section{Holger Krimmer Ziviz}

- Vereine sind die am häufigsten genutzte Rechtsform der organisierten Zivilgesellschaft. 2016 gab es 603886 eingetragene Vereine in Deutschland (S. 13).

- Stiftungen sind mit einem Bestand von 22274 (Ende 2017) die Rechtsform der organisierten Zivilgesellschaft mit den größten Wachstumsraten in den letzten 20 Jahren (S. 36).

- In 2014 waren nach den Daten des Freiwilligensurveys 43,6 Prozent der deutschen Bevölkerung ab 14 Jahren freiwillig engagiert (S. 59).

- Von 1999 bis 2014 sank der Anteil des organisationsgebundenen Engagements von 55,8 auf 52,1 Prozent (Freiwilligensurvey). Dafür stieg der Anteil des Engagements in ,individuell organisierten Gruppen“ (S. 80).

- Von 2007 bis 2016 stieg der Anteil der beschäftigten MitarbeiterInnen (sozialversicherungspflichtig und geringfügig Beschäftigte) von 2,9 auf 3,7 Millionen (IAB Betriebspanel). Der Beschäftigungsanstieg im gemeinnützigen Sektor überstieg damit den allgemeinen Beschäftigungsanstieg (S. 93).

- Mit 61 Prozent entfällt der größte Anteil der Beschäftigten auf den Bereich „Sozial- und Gesundheitswesen“ (S. 98).

- 51 Prozent der Vereine in Deutschland arbeiten mit einem jährlichen Budget von weniger als 10 ooo Euro (S. 115).

- Im Jahr 2016 haben nach Daten des GfK CharityScope (Auswertung für den Deutschen Spendenrat) 33 Prozent der deutschen Bevölkerung an eine gemeinnützige Organisation oder Kirche Geld gespendet (S. 125).

- Die Hochrechnungen für das jährliche Spendenvolumen in Deutschland schwanken zwischen 3,7 Milliarden und 8,o Milliarden Euro. Das Deutsche Zentralinstitut für soziale Fragen (DZI) kommt für 2014 auf ein Gesamtvolumen von 6,7 Milliarden Euro (S. 136). 
- Wertorientierungen und Kirchgangshäufigkeit weisen nach Daten des ALLBUS einen starken Zusammenhang mit der Vereinsmitgliedschaft von BürgerInnen auf (S. 149 ff.).

- Mit (Häufigkeit der) Ausübung eines freiwilligen Engagements steigt nach Daten des SOEP die individuelle Lebenszufriedenheit (S. 154).

Open Access Dieses Kapitel wird unter der Creative Commons Namensnennung 4.0 International Lizenz (http://creativecommons.org/licenses/by/4.0/deed.de) veröffentlicht, welche die Nutzung, Vervielfältigung, Bearbeitung, Verbreitung und Wiedergabe in jeglichem Medium und Format erlaubt, sofern Sie den/die ursprünglichen Autor(en) und die Quelle ordnungsgemäß nennen, einen Link zur Creative Commons Lizenz beifügen und angeben, ob Änderungen vorgenommen wurden.

Die in diesem Kapitel enthaltenen Bilder und sonstiges Drittmaterial unterliegen ebenfalls der genannten Creative Commons Lizenz, sofern sich aus der Abbildungslegende nichts anderes ergibt. Sofern das betreffende Material nicht unter der genannten Creative Commons Lizenz steht und die betreffende Handlung nicht nach gesetzlichen Vorschriften erlaubt ist, ist für die oben aufgeführten Weiterverwendungen des Materials die Einwilligung des jeweiligen Rechteinhabers einzuholen.

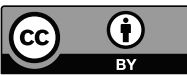

